\title{
Faktor pada perilaku Ibu dalam pemberian MPASI anak 6-24 bulan di Puskesmas Perumnas, Kendari
}

Rosnah ${ }^{1}$, Kristiani², Endang Pamungkasiwi $^{3}$

\begin{abstract}
Background: The problem of growth among underfives in Indonesia is related to the number of infants that are given complementary feeding since the age of one month. It influenced the prevalence of undernourishment $3.25 \%$ and malnutritionat District of Kadia become higher. Those nutrition problem can be affected by inability to provide foods as needed by members of the family, knowledge and behavior of the family in food selection, cook and distribute the food in the family. Another problem is lack of mothers' attention to monitor the child growth and development

Objective: To study the factors associated with mothers' behavior in the supply of complementary breastfeeding to infants of 6-24 months at Perumnas Health Center Subdistrict of Kadia Kendari Municipality.

Method: This analytical study used a cross sectional design and quantitative and qualitative method. Subject were mothers' of underfives who fulfilled inclusion criteria at the working area of Perumnas Health Center District of Kadia Kendari Municipality. Samples were taken using simple random sampling technique. Research instruments were questionnaire and indepth interview guide. Data analysis used chi square and double logistic regression test. Qualitative data were analyzed manually and presented in narration.

Result: Predisposition factors significantly associated with mothers' behavior in the supply of complementary breastfeeding were mothers' education ( $p=0.025$; OR=3.27), family income $(p=0.007$; OR=4.65), knowledge of mothers $(p=0.05$; $O R=2.75)$, and mothers' attitude ( $p=0.027 ; O R=2.92)$. Another supporting factor, i.e. participation of mothers in the integrated service post (posyandu) was significantly associated with behavior in the supply of complementary breastfeeding $(p=0.008 ; O R=3.65)$. Encouraging factors associated with the behavior of mother in the supply of complementary breastfeeding were support of the health staff $(p=0.005 ; O R=4.21)$ and the family $(p=0.041 ; O R=4.22)$.

Conclusion: The result of multivariate analysis showed that the factor most dominantly associated with the behavior in the supply of complementary breastfeeding was education of mothers $(p=0.012 ; O R=5,40)$.
\end{abstract}

KEYWORDS: behavior, complementary breastfeeding, infants of 6 - 24 months

\begin{abstract}
ABSTRAK
Latar Belakang: Masalah gangguan pertumbuhan balita di Indonesia berkaitan dengan banyaknya bayi yang sudah diberi makanan pendamping ASI (MPASI) sejak usia kurang dari atau 1 bulan. Hal ini mengakibatkan prevalensi gizi kurang dan buruk di Kecamatan Kadia cukup tinggi. Masalah gizi ini dipengaruhi oleh tingkat kemampuan menyediakan pangan sesuai dengan kebutuhan anggota keluarga, pengetahuan dan perilaku keluarga dalam memilih, mengolah, dan membagi makanan di tingkat rumah tangga. Permasalahan lain kurangnya perhatian ibu untuk memantau tumbuh kembang balitanya.

Tujuan: Mengetahui faktor-faktor yang berhubungan dengan perilaku ibu dalam pemberian MPASI pada anak usia 6-24 bulan di Puskesmas Perumnas Kecamatan Kadia, Kota Kendari.

Metode: Jenis penelitian ini adalah analitik dengan rancangan cross sectional, menggunakan metode kuantitatif dan kualitatif. Subjek adalah ibu balita yang memenuhi kriteria inklusi di wilayah kerja Puskesmas Perumnas Kecamatan Kadia, Kota Kendari. Jumlah sampel sebanyak 97 subjek. Pengambilan sampel secara simple random sampling. Data dikumpulkan dengan panduan wawancara mendalam dan dianalisis dengan Chi-Square dan uji regresi logistik berganda. Data kualitatif dianalisis secara manual dan disajikan dalam bentuk narasi.

Hasil: Dari faktor-faktor predisposisi, yang mempunyai hubungan bermakna dengan perilaku ibu dalam pemberian MPASI adalah pendidikan ibu $(p=0,025 ; R P=3,27)$, pendapatan per kapita keluarga $(p=0,007 ; R P=4,65)$, pengetahuan ibu $(p=0,05 ; R P=2,75)$, dan sikap ibu ( $p=0,027 ; R P=2,92)$ dengan perilaku pemberian MPASI. Dari faktor pendukung, partisipasi ibu ke posyandu mempunyai hubungan bermakna dengan perilaku pemberian MPASI $(p=0,008 ; R P=3,65)$, sedangkan dari faktor pendorong yang berhubungan dengan perilaku ibu dalam pemberian MPASI adalah dukungan petugas kesehatan ( $p=0,005 ; R P=4,21)$ dan dukungan keluarga $(p=0,041 ; R P=4,22)$.
\end{abstract}

\footnotetext{
1.Poltekkes Kendari jurusan Gizi, Jl. Patimura No.45 Kendari, email: rosnahsyaifudin@yahoo.co.id

2.Pusat Kesehatan Masyarakat Salaman, Jl. Mungkidan, Danurejo, Magelang

3.Dinas Kesehatan Provinsi Daerah Istimewa Yogyakarta, Jl. Tompeyan III/ 210 Yogyakarta
} 
Kesimpulan: Dari hasil analisis multivariat diperoleh hasil bahwa faktor paling dominan yang berhubungan dengan perilaku pemberian MPASI adalah pendidikan ibu $(p=0,015 ; R P=5,40)$.

KATA KUNCI: perilaku, pemberian MPASI, anak usia 6-24 bulan.

\section{PENDAHULUAN}

Masalah kekurangan energi protein (KEP) di Indonesia masih menjadi masalah yang belum dapat diatasi secara total. Analisis data susenas (survei sosial ekonomi nasional) tahun 2002 menunjukkan bahwa prevalensi KEP di negara ini masih tinggi, yaitu di atas $25 \%$. KEP yang terjadi pada bayi akan berdampak pada gangguan psikologis dan sosial, sekaligusmenyebabkan keterlambatan pertumbuhan (growth faltering) secara klinis (1). Masalah gangguan pertumbuhan pada anak balita di Indonesia berkaitan dengan banyaknya bayi yang sudah diberi makanan pendamping ASI (MPASI) sejak usia $\leq 1$ bulan. Pemberian MPASI pada bayi sebelum usia 6 bulan dapat meningkatkan risiko gangguan pencernaan dan infeksi karena kontaminasi oleh mikroba seperti sakit perut, sembelit (susah buang air besar), dan alergi (2).

Prevalensi gizi kurang dan buruk pada balita di Provinsi Sulawesi Tenggara tahun 2007 mencapai $13,6 \%$ dan 2,7\%,di Kota Kendari mencapai 3,25\%dan $0,86 \%$, di Kecamatan Kadia sebesar 2,37\% dan 1,11\% (3). Masalah gizi ini dipengaruhi oleh banyak faktor, antara lain: tingkat kemampuan keluarga dalam menyediakan pangan sesuai dengan kebutuhan anggota keluarga, pengetahuan dan perilaku keluarga dalam memilih, mengolah, dan membagi makanan di tingkat rumah tangga, ketersediaan air bersih dan fasilitas sanitasi dasar, serta ketersediaan dan aksesibilitas terhadap pelayanan kesehatan dan gizi masyarakat yang berkualitas(4).Faktor lain yang juga mempengaruhi permasalahan gizi adalah kurangnya perhatian ibu tentang pentingnya pemantauan tumbuh kembang balita secara teratur di posyandu. Hal ini dapat dilihat dari cakupan D/S (rasio jumlah balita yang datang ditimbang dengan jumlah balita di desa) Kota Kendari umumnya dan wilayah kerja Puskesmas Perumnas khususnya pada tahun 2007 yang masih jauh dibawah target nasional, yaitu sebesar42,8 dan 32,3\%(target nasional adalah $\geq 80 \%$ ) (3).

Keadaan tersebut menggambarkan masalah gizi dan kesehatan di Kota Kendari, khususnya Kecamatan Kadia dipengaruhi oleh pengetahuan dan perilaku ibu mengenai gizi dan kesehatan yang kurang baik. Untuk dapat memperbaiki perilaku tersebut, diperlukan pemahaman faktor perilaku dan sosial budaya yang mempengaruhinya. Kemampuan seseorang untuk menerapkan pengetahuan gizi mempengaruhi sikap seseorang terhadap suatu makanan(5). Pengetahuan dan sikap tersebut kemudian akan dinyatakan dalam bentuk tindakan makan atau memilih makanan (6).
Penelitian ini bertujuan untuk mengetahui faktorfaktor yang berhubungan dengan perilaku ibu dalam pemberian MPASI pada anak 6-24 bulan di wilayah kerja Puskesmas Perumnas Kota Kendari.

\section{BAHAN DAN METODE}

Jenis penelitian ini adalah analitik dengan rancangan cross sectional. Metode penelitian ini merupakan gabungan dari penelitian kuantitatif dan kualitatif. Penelitian dilaksanakan di wilayah kerja Puskesmas Perumnas Kecamatan Kadia, Kota Kendari. Populasi penelitian ini adalah seluruh ibu-ibu yang mempunyai anak usia 6-24 bulan yang ada di wilayah kerja Puskesmas Perumnas Kecamatan Kadia Kota Kendari. Besar sampel ditentukan dengan rumus untuk survei sampel dengan pendugaan dalam jarak "d" persen (7) yaitu sebanyak 97orang dan akan diambil secara simple random sampling. Kriteria inklusi antara lain: ibu yang mempunyai anak usia 6-24 bulan, menyusui, memiliki KMS (kartu menuju sehat), dan bersedia menjadi subjek penelitian, sedangkan kriteria eksklusi yaitu: ibu dengan baduta (bawah dua tahun) yang mempunyai penyakit kronis dan kelainankongenital.

Variabel bebas yang diteliti dalam penelitian ini dibagi menjadi faktor predisposisi (tingkat pendidikan, pekerjaan, umur ibu, pengetahuan, pendapatan per kapita/ bulan, jumlah balita dalam keluarga, besar keluarga, dan sikap ibu); faktor pendukung (partisipasi ke posyandu); dan faktor pendorong (dukungan kader posyandu dan petugas kesehatan, adanya penyuluhan gizi, MPASI, dan dukungan suami/anggota keluarga). Adapun variabel terikat adalah perilaku ibu dalam pemberian MPASI.

Alat bantu yang digunakan untuk memperlancar proses pengumpulan data kuantitatif berupa lembar kuesioner. Pengumpulan data kualitatif dilakukan dengan wawancara mendalam terhadap subjek penelitian. Sebelum digunakan untuk penelitian, kuesioner diuji validitas dan reliabilitasnya. Uji validitas menggunakan metode statistik korelasi Pearson product moment ( $r)$ dengan mengkorelasikan skor masing-masing pertanyaan dengan skor totalnya, kemudian diolah menggunakan perangkat program komputer. Angka korelasi ( $r$ ) yang kurang dari 0,361 pada taraf kepercayaan $5 \%$ dinyatakan gugur. Hasil uji reliabilitas instrumen penelitian diperoleh nilaialphauntuk variabelpengetahuan, sikap, dan perilaku berturut-turutsebesar 0,889; 0,918; dan 0,884 (reliable).

Data kemudian di analisis melalui 3 tahap, antara lain: analisis univariat menggunakan tabel distribusi frekuensi dan persentase; dilanjutkan analisis bivariat dengan 
uji statistik Chi-Square, rasio prevalensi (RP) dengan confident interval $(\mathrm{Cl}) 95 \%$, pada tingkat kemaknaan $\mathrm{p}<0,05$.Analisis multivariat kemudian dilakukandengan regresi logistik ganda pada tingkat kemaknaan $p<0,05$ dan nilai RP dengan $\mathrm{C} 195 \%$.

\section{HASIL DAN BAHASAN}

\section{Faktor predisposisi}

Analisis univariat.Pada penelitian ini, analisis univariat dilakukan terhadap karakteristik subjek yang didasarkan pada faktor predisposisi, faktor pendukung, dan faktor pendorong. Faktor predisposisi yang diteliti dapat dilihat pada Tabel 1.

Tabel 1. Distribusi frekuensi karakteristik ibu berdasarkan faktor predisposisi

\begin{tabular}{|c|c|c|}
\hline \multirow{2}{*}{ Variabel } & \multicolumn{2}{|c|}{ Jumlah } \\
\hline & $\mathbf{n}$ & $\%$ \\
\hline \multicolumn{3}{|l|}{ Umur ibu } \\
\hline$\leq 21$ tahun & 34 & 35,1 \\
\hline$>21$ tahun & 63 & 64,9 \\
\hline \multicolumn{3}{|l|}{ Pendidikan ibu } \\
\hline SLTP ke bawah & 37 & 38,1 \\
\hline SMA ke atas & 60 & 61,9 \\
\hline \multicolumn{3}{|l|}{ Pekerjaan ibu } \\
\hline Tidak bekerja & 80 & 82,5 \\
\hline Bekerja & 17 & 17,5 \\
\hline \multicolumn{3}{|l|}{ Pendapatan per kapita/bulan keluarga } \\
\hline Tinggi ( >UMR Kota Kendari, Rp 950.000,-) & 19 & 19,6 \\
\hline Rendah ( $\leq$ UMR Kota Kendari, Rp 950.000,-) & 78 & 80,4 \\
\hline \multicolumn{3}{|l|}{ Jumlah balita dalam keluarga } \\
\hline 1 orang & 79 & 81,4 \\
\hline$>1$ orang & 18 & 18,6 \\
\hline \multicolumn{3}{|l|}{ Ukuran keluarga } \\
\hline$\leq 4$ orang & 72 & 74,2 \\
\hline$>4$ orang & 25 & 25,8 \\
\hline \multicolumn{3}{|l|}{ Pengetahuan } \\
\hline Tinggi ( $\geq$ nilai median total skor ) & 59 & 58,8 \\
\hline Rendah (<nilai median total skor) & 38 & 41,2 \\
\hline \multicolumn{3}{|l|}{ Sikap } \\
\hline Baik ( $\geq$ nilai median total skor) & 48 & 49,5 \\
\hline Tidak baik (<nilai median total skor ) & 49 & 50,5 \\
\hline \multicolumn{3}{|l|}{ Perilaku } \\
\hline Baik ( $\geq$ nilai median total skor) & 33 & 34,0 \\
\hline Tidak baik (<nilai median total skor) & 64 & 66,0 \\
\hline
\end{tabular}

Tabel 1 menunjukkan bahwa sebagian besaribu berumur $>21$ tahun, berpendidikan SLTA ke atas, tidak bekerja, pendapatan per kapita/bulan $\leq U M R$ Kota Kendari, jumlah baduta rata-rata dalam keluarga berjumlah 1 anak, jumlah anggota keluarga ibu $\leq 4$ orang, mempunyai pengetahuan tinggi, mempunyai sikap tidak baik, dan berperilaku tidak baik dalam pemberian MPASI.

Karakteristik subjek berdasarkan faktor pendorong dan pendukung perilaku ibu dalam pemberian MPASI dapat dilihat pada Tabel 2.
Tabel 2. Distribusi frekuensi subjek penelitian berdasarkan faktor pendorong dan pendukung

\begin{tabular}{lcc}
\hline \multicolumn{1}{c}{ Akses ke pelayanan kesehatan } & $\mathbf{n}$ & $\%$ \\
\hline $\begin{array}{l}\text { Partisipasi (D/S) ke posyandu } \\
\quad \text { Aktif ( } \geq 4 \text { kali kunjungan) dalam 6 bulan }\end{array}$ & 51 & 52,6 \\
$\quad$ terakhir & 46 & 47,4 \\
$\quad$ Tidak aktif (<4 kali kunjungan dalam 6 & & \\
$\quad$ bulan terakhir) & & \\
Dukungan petugas kesehatan & 41 & 42,3 \\
$\quad$ Tidak & 56 & 57,7 \\
$\quad$ Ada & & \\
Dukungan kader posyandu & 67 & 69,1 \\
$\quad$ Tidak & 30 & 30,9 \\
$\quad$ Ada & & \\
Dukungan keluarga (suami/anggota keluarga & & \\
lain) & 22 & 22,7 \\
$\quad$ Tidak & 75 & 77,3 \\
$\quad$ Ada & & \\
\hline
\end{tabular}

Tabel 2 menunjukkan bahwa sebagian besar subjek aktif berpartisipasi ke posyandu, mendapat dukungan dari petugas kesehatan, tidak mendapat dukungan dari kader posyandu,dan mendapat dukungan dari keluarga.

Analisis bivariat. Analisis bivariat yang diklasifikasikan menurut faktor predisposi dapat dilihat pada Tabel 3. Berdasarkan Tabel 3, diketahui bahwa antara pendidikan ibu dan pengetahuan terdapat hubungan yang bermakna dengan perilaku pemberian MPASI $(p<0,05)$. Ibu berpendidikan SSLTP mempunyai probabilitas 3,27 kali untuk berperilaku tidak baik dibandingkan dengan ibu yang berpendidikan $\geq S L T A(p=0,025)$. Pada ibu dengan level pendidikan tinggi, dimungkinkan diikuti juga dengan pemahaman ibu mengenai perilaku pemberian makanan pada bayi yang benar. Pendidikan orang tua merupakan salah satu faktor yang penting dalam tumbuh kembang anak. Karena dengan pendidikan yang baik, maka orang tua dapat menerima segala informasi dari luar terutama tentang cara pengasuhan anak yang baik (dalam hal ini perilaku pemberian MPASI yang baik), bagaimana menjaga kesehatan anaknya, pendidikannya, dan sebagainya (8).

Faktor pekerjaan tidak berhubungan secara bermakna dengan perilaku pemberian MPASI $(p>0,05)$ (Tabel 3). Hal ini disebabkan ibu bekerja dan tidak bekerjamasih kurang baik dalam memberikan makan pada baduta (jenis maupun frekuensi pemberian makan). Makanan yang diberikan sebagian besar masih kurang beragam dengan frekuensi pemberian makan yang kurang dari tiga kali sehari. Sebagian besar ibu memberikan makanan tambahan pada baduta sebelum berusia 6 bulan. Pada ibu bekerja seringkali mengurangi ketersediaan waktu untuk bersama anak, lebih cepat mengurangi pemberian ASI, serta lebih cepat memberikan makanan tambahan bagi anaknya.

Faktor umur ibu juga menunjukkan hubungan yang tidak bermakna dengan perilaku pemberian MPASI $(p>0,05)$ (Tabel 3). Salah satu penyebabnya baik pada ibu 
yang berusia $\leq 21$ tahun atau $>21$ tahun sebagian besar karena berperilaku tidak baik dalam pemberian MPASI. Hal ini dapat terjadi antara lain karena sebagian besar ibu berusia relatif muda dan jumlah anak balita 1 orang, sehingga belum banyak pengalaman mengenai pemberian makanan bagi bayi.

Faktor pendapatan per kapita juga berhubungan bermakna dengan perilaku pemberian MPASI $(p>0,05)$ (Tabel 3). Tingkat pendapatan yang rendah mempengaruhi daya beli masyarakat termasuk pada bahan makanan bergizi, sehingga menyebabkan konsumsi makanan bergizi menjadi berkurang. Keadaan ini dapat disebabkan oleh adanya peningkatan pendapatan keluarga akan diiringi dengan adanya belanja untuk kebutuhan makanan anaknya, sehingga ibu yang mempunyai kelebihan pendapatan mengalokasikan pendapatannya untuk membeli bahan pangan untuk anaknya.

Hubungan bermakna juga ditemukan antara ukuran keluarga dengan perilaku pemberian MPASI $(p>0,05)$ (Tabel 3). Adanya jumlah keluarga yang banyak lebih dimungkinkan perhatian ibu akan tercurah pada anggota keluarga lain. Keadaan ini merupakan salah satu hal yang berkaitan dengan perilaku tidak baik ibu dalam pemberian MPASI pada anaknya.

Berdasarkan jumlah balita, diperoleh hasil bahwa tidak terdapat hubungan yang bermakna antara jumlah balita dengan perilaku pemberian MPASI $(p>0,05)$ (Tabel
3). Jumlah anak yang banyak pada keluarga yang sosial ekonominya cukup, akan mengakibatkan berkurangnya perhatian dan kasih sayang yang diterima anak. Hal ini diperparah jika jarak anak terlalu dekat. Sebaliknya, pada keluarga dengan keadaan sosial ekonomi yang kurang, jumlah anak yang banyak akan mengakibatkan selain kurangnya kasih sayang dan perhatian pada anak, juga kebutuhan primer seperti makanan, sandang dan perumahan pun tidak terpenuhi (8).

Berdasarkan hasil penelitian kualitatif, diketahui bahwa pengetahuan responden mengenai umur berapa baduta dapat diberi makanan atau minuman selain ASI atau seperti makanan yang dikonsumsi anggota keluarga lain masih kurang baik. Pengetahuan masyarakat yang rendah tentang makanan bayi dapat mengakibatkan terjadinya kekurangan gizi pada bayi. Fakta menunjukkan bahwa para ibu yang menyusui bayinya masih beranggapan bahwa ASI dapat memenuhi kebutuhan bayi sampaianak dapat mengajukan permintaan untuk makan sendiri (kirakira berusia satu tahun). Seharusnya, setelah berumur satu tahun, bayi mulai mengenal makanan yang dimakan oleh seluruh anggota keluarga. Pemberian ASI tetap dilanjutkan hingga anak berusia 24 bulan (2).

Pengetahuan responden mengenai akibat pemberian MPASI dini pada baduta masih kurang baik. Masalah gangguan pertumbuhan pada anak balita yang banyak terjadi diduga berkaitan dengan banyaknya bayi yang

Tabel 3. Hubungan antara faktor predisposisi dengan perilaku ibu dalam pemberian MPASI anak usia 6-24 bulan

\begin{tabular}{|c|c|c|c|c|c|c|}
\hline \multirow{2}{*}{ Variabel } & \multicolumn{2}{|c|}{ Perilaku MPASI } & \multirow{2}{*}{$\mathbf{R P}$} & \multirow{2}{*}{$\chi^{2}$} & \multirow{2}{*}{$\mathbf{p}$} & \multirow{2}{*}{$95 \% \mathrm{Cl}$} \\
\hline & Tidak baik & Baik & & & & \\
\hline \multicolumn{7}{|l|}{ Pendidikan ibu } \\
\hline$\leq S L T P$ & $30(81,1 \%)$ & $7(18,9 \%)$ & 3,27 & 5,03 & 0,025 & $1,24-8,63$ \\
\hline$\geq$ SLTA & $34(56,7 \%)$ & $26(43,3 \%)$ & & & & \\
\hline \multicolumn{7}{|l|}{ Pekerjaan } \\
\hline Bekerja & $13(76,5 \%)$ & $4(23,5 \%)$ & 1,84 & 0,52 & 0,469 & $0,55-6,19$ \\
\hline Tidak bekerja & $51(63,8 \%)$ & $29(36,3 \%)$ & & & & \\
\hline \multicolumn{7}{|l|}{ Usia ibu } \\
\hline$\leq 21$ tahun & $25(73,5 \%)$ & $9(26,5 \%)$ & 1,71 & 1,33 & 0,249 & $0,68-4,27$ \\
\hline$>21$ tahun & $39(61,9 \%)$ & $24(38,1 \%)$ & & & & \\
\hline \multicolumn{7}{|c|}{ Pendapatan per kapita } \\
\hline$\leq$ UMR & $57(73,1 \%)$ & $21(26,9 \%)$ & 4,65 & 7,39 & 0,007 & $1,61-13,40$ \\
\hline$>$ UMR & $7(36,8 \%)$ & $12(63,2 \%)$ & & & & \\
\hline \multicolumn{7}{|l|}{ Ukuran keluarga } \\
\hline$>4$ orang & $21(84,0 \%)$ & $4(16,7 \%)$ & 3,54 & 3,85 & 0,035 & $1,10-11,39$ \\
\hline$\leq 4$ orang & $43(59,7 \%)$ & $29(40,3 \%)$ & & & & \\
\hline \multicolumn{7}{|l|}{ Jumlah balita } \\
\hline$>1$ balita & $12(66,7 \%)$ & $6(33,3 \%)$ & 0.96 & 0,00 & 1,000 & $0,32-2,84$ \\
\hline 1 balita & $52(65,8 \%)$ & $27(34,2 \%)$ & & & & \\
\hline \multicolumn{7}{|l|}{ Pengetahuan MPASI } \\
\hline Rendah & $30(78,9 \%)$ & $8(21,1 \%)$ & 2,75 & 3,77 & 0,025 & $1,08-7,02$ \\
\hline Tinggi & $34(57,6 \%)$ & $25(42,4 \%)$ & & & & \\
\hline \multicolumn{7}{|l|}{ Sikap MPASI } \\
\hline Tidak baik & $38(77,6 \%)$ & $11(22,4 \%)$ & 2,92 & 4,91 & 0,027 & $1,21-7,04$ \\
\hline Baik & $26(54,2 \%)$ & $22(45,8 \%)$ & & & & \\
\hline
\end{tabular}

* Bermakna $(p<0,05)$ 
sudah diberi MPASI sejak usia 1 bulan, bahkan sebelum usia 1 bulan. Pemberian MPASI pada bayi sebelum usia 4 bulan meningkatkan resiko gangguan pencernaan dan infeksi karena kontaminasi oleh mikroba seperti sakit perut, sembelit (susah buang air besar), dan alergi (2).

Berdasarkan Tabel 3, diperoleh hasil adanya hubungan bermakna antara sikap ibu dengan perilaku pemberian MPASI $(p>0,05)$. Keadaan ini menunjukkan bahwa sikap yang negatif lebih memungkinkan ibu untuk tidak menerima perilaku pemberian MPASI, tetapi dengan adanya sikap yang positif akan memudahkan seseorang untuk menerima perilaku tersebut. Sikap merupakan reaksi atau respon yang masih tertutup dari seseorang terhadap stimulus atau objek. Sikap belum otomatis terwujud dalam suatu tindakan. Untuk mendukung terwujudnya sikap menjadi suatu perbuatan nyata atau praktik, diperlukan faktor pendukung atau suatu kondisi yang memungkinkan antara lain fasilitas. Selain faktor fasilitas diperlukan faktor dukungan (support) dari pihak lain, seperti suami/istri, orang tua/ mertua, anak, dll(9).

\section{Faktor pendukung dan pendorong}

Faktor pendorong ibu yang diteliti dalam penelitian ini adalah partisipasi ibu ke posyandu, sedangkan faktor pendukung antara lain: dukungan petugas kesehatan, kader posyandu, dan keluarga yang dapat dilihat pada Tabel 4. Tabel 4 menunjukkan terdapat hubungan yang bermakna antara faktor pendukung (partisipasi ibu ke posyandu) dengan perilaku pemberian MPASI $(p<0,05)$. Jika dilihat dari aspek risiko, ibu yang tidak berpartisipasi aktif ke posyandu mempunyai rasio prevalensi 3,65 kali untuk berperilaku tidak baik dalam pemberian MPASI dibanding dengan ibu yang aktif berpartisipasi ke posyandu.

Berdasarkan analisis bivariat, diperoleh hasil terdapat hubungan yang bermakna antara partisipasi ibu ke posyandu dengan perilaku pemberian MPASI. Keadaan ini dapat disebabkan oleh di posyandu seorang ibu mendapatkan berbagai informasi mengenai banyak hal tentang anaknya khususnya yang berkaitan dengan pemberian MPASI. Dengan adanya informasi yang banyak oleh seorang ibu lebih dimungkinkan bagi ibu untuk mempunyai perilaku yang baik tentang pemberian MPASI bagi anaknya. Hal ini menunjukkan bahwa adanya perilaku pemberian MPASI dipengaruhi oleh informasi yang diterima ibu yang aktif berkunjung ke posyandu.

Pengetahuan dapat membentuk keyakinan tertentu sehingga seseorang berperilaku sesuai dengan keyakinannya tersebut. Kemampuan seseorang untuk menerapkan pengetahuan gizi mempengaruhi sikap seseorang terhadap suatu makanan. Pengetahuan dan sikap tersebut kemudian akan dinyatakan dalam bentuk tindakan makan atau memilih makanan (10).

Berdasarkan faktor pendorong, diperoleh hasil terdapat hubungan yang bermakna antara dukungan petugas kesehatan dengan perilaku pemberian MPASI $(p<0,05)$, namun tidak terdapat hubungan yang bermakna antara dukungan kader posyandu dengan perilaku pemberian MPASI ( $p>0,05)$. Hal ini disebabkan oleh ibuibu baduta yang ada di wilayah penelitian lebih mengikuti petunjuk dari petugas kesehatan yang ada di puskesmas dibandingkan dengan petunjuk kader posyandu mengenai pemberian makan pada baduta.Faktor dukungan suami atau anggota keluarga lain berhubungan bermakna dengan perilaku pemberian MPASI. Agar praktik menyusui dapat lebih berhasil,seorang ibu perlu dukungan psikologis dari keluarga dekat, terutama wanita seperti ibu, ibu mertua, kakak wanita, teman/wanita lain yang telah berpengalaman dan berhasil dalam menyusui. Diperlukan juga dukungan dari suami yang mengerti bahwa ASI adalah makanan yang terbaik untuk bayinya (11). Adanya supervisi bidan yang disertai penyuluhan, dapat meningkatkan kepatuhan

Tabel 4. Hubungan antara partisipasi ibu ke posyandu, faktor pendorong dengan perilaku pemberian MPASI.

\begin{tabular}{|c|c|c|c|c|c|c|}
\hline \multirow{2}{*}{ Variabel } & \multicolumn{2}{|c|}{ Perilaku MPASI } & \multirow{2}{*}{$\mathbf{R P}$} & \multirow{2}{*}{$\chi^{2}$} & \multirow{2}{*}{$\mathbf{p}$} & \multirow{2}{*}{$95 \% \mathrm{Cl}$} \\
\hline & Tidak baik & Baik & & & & \\
\hline \multicolumn{7}{|c|}{$\begin{array}{l}\text { Faktor pendukung } \\
\text { Partisipasi ibu ke posyandu }\end{array}$} \\
\hline Tidak aktif & $37(80,4 \%)$ & $9(19,6 \%)$ & 3,65 & 6,96 & 0,008 & $1,46-9,10$ \\
\hline Aktif & $27(52,9 \%)$ & $24(47,1 \%)$ & & & & \\
\hline \multicolumn{7}{|l|}{ Faktor pendorong } \\
\hline \multicolumn{7}{|c|}{ Dukungan petugas kesehatan } \\
\hline Tidak ada & $34(82,9 \%)$ & $7(17,1 \%)$ & 4,21 & 7,82 & 0,005 & $1,59-11,08$ \\
\hline Ada & $30(53,6 \%)$ & $26(46,4 \%)$ & & & & \\
\hline \multicolumn{7}{|c|}{ Dukungan kader posyandu } \\
\hline Tidak ada & $47(70,1 \%)$ & $20(29,9 \%)$ & 1,79 & 1,13 & 0,288 & $0,73-4,38$ \\
\hline Ada & $17(56,7 \%)$ & $13(43,3 \%)$ & & & & \\
\hline \multicolumn{7}{|l|}{ Dukungan keluarga } \\
\hline Tidak ada & $19(86,4 \%)$ & $3(13,6 \%)$ & 4,22 & 4,15 & 0,041 & $1,14-15,52$ \\
\hline Ada & $45(60,0 \%)$ & $30(40,0 \%)$ & & & & \\
\hline
\end{tabular}

* Bermakna $(p<0,05)$ 
minum tablet besi secara nyata pada ibu hamil di daerah intervensi daripada di daerah kontrol.

Untuk mencapai predikat kadarzi diperlukan serangkaian kegiatan pemberdayaan diberbagai tingkat, salah satunya adalah dengan pemberdayaan petugas pembina yang langsung berhadapan dengan keluarga binaan, yaitu kader posyandu/gizi/kesehatan.Namun demikian, kendala yang dihadapi adalah masih kurangnya tingkat pengetahuan kader posyandu/gizi/kesehatan dalam upaya pembinaan kadarzi, terutama untuk melakukan konseling gizi keluarga (12).

\section{Analisis multivariat faktor predisposisi, pendukung,dan pendorong}

Tabel 5 menunjukkan faktor-faktor yang berhubungan dengan kejadian perilaku tidak baik dalam pemberian MPASI.

Faktor predisposisi. Berdasarkan analisis multivariat, variabel yang berkontribusi paling dominan dalam faktor predisposisi adalah pendapatan keluarga $(p=0,014 ; R P=4,88)$ dibanding dengan variabel lain (pendidikan ibu, ukuran keluarga, jenis dan frekuensi MPASI, dan sikap ibu). Pendapatan yang rendah disamping berdampak pada kemampuan daya beli makanan, juga berdampak terhadap kesempatan untuk memilih makanan yang berkualitas. Hasil penelitian ini menunjukkan bahwa meskipun pengetahuan ibu dalam pemberian MPASI cukup baik, namun realitas ekonomi menjadi benturan utama, sehingga pengetahuan tidak dapat diimplementasikan dalam kesehariannya.

Pengetahuan responden mengenai pentingnya untuk memberikan makanan yang beraneka ragam pada baduta sudah baik, tetapi adanya keterbatasan ekonomi menyebabkan mereka memberikan makanan atau minuman pada anak sesuai dengan kemampuan keluarga.Pekerjaan yang berhubungan dengan pendapatan merupakan faktor yang paling menentukan kuantitas dan kualitas makanan. Rendahnya pendapatan orang miskin dan lemahnya daya beli mereka tidak memungkinkan untuk mengatasi kebiasaan makan dan cara-cara tertentu yang menghalangi perbaikan gizi yang efektif, terutama untuk anak-anak mereka. Apabila penghasilan keluarga meningkat, biasanya penyediaan laukpauk meningkat mutunya (13).

Faktor pendukung. Berdasarkan analisis multivariat, pada variabel pendukung menunjukkan bahwa ibu yang tidak aktif berpartisipasi ke posyandu mempunyai risiko sebesar 4,34 kali untuk berperilaku tidak baik dalam pemberian MPASI dibanding dengan ibu yang berpartisipasi ke posyandu. Pada ibu yang tidak rajin datang berpartisipasi ke posyandu, secara otomatis kurang mendapat informasi mengenai bagaimana memberikan MPASI yang benar. Kondisi ibu yang tidak aktif datang ke posyandu dan didukung oleh pendidikan ibu yang rendah, lebih memungkinkan bagi ibu untuk berperilaku tidak baik dalam pemberian MPASI karena ibu tidak memahami bagaimana cara pemberian makanan bayi yang benar.

Faktor pendorong. Berdasarkan analisis multivariat, variabel yang lebih dominan berdampak pada perilaku tidak baik dalam pemberian makanan bayi pada faktor pendorong adalah dukungan petugas kesehatan dibanding faktor dukungan keluarga. Anjuran dari petugas kesehatan lebih diperhatikan oleh seorang ibu karena petugas kesehatan dianggap lebih memahami dan lebih mengetahui mengenai pemberian makanan bayi. Pada umumnya, para ibu mau patuh dan menurut nasihat petugas kesehatan sehingga nasihat yang diberikan oleh ahli kebidanan, dokter anak, atau bidan akan diikuti oleh ibu-ibu untuk menyusui sendiri bayinya (11).

Dukungan dari petugas kesehatan memegang peranan penting dalam mengubah perilaku ibu yang masih tidak baik dalam masyarakat, khususnya dalam pemberian MPASI. Agar terjadi perubahan perilaku dalam masyarakat, perlu

Tabel 5. Analisis multivariat faktor-faktor yang berhubungan dengan kejadian perilaku tidak baik dalam pemberian MPASI

\begin{tabular}{|c|c|c|c|c|c|c|c|c|c|}
\hline \multirow{2}{*}{ Faktor risiko } & \multicolumn{3}{|c|}{ Model 1} & \multicolumn{3}{|c|}{ Model 2} & \multicolumn{3}{|c|}{ Model 3} \\
\hline & RP & $95 \% \mathrm{Cl}$ & $\mathbf{p}$ & RP & $95 \% \mathrm{Cl}$ & $\mathbf{p}$ & RP & $95 \% \mathrm{Cl}$ & $\mathbf{p}$ \\
\hline \multicolumn{10}{|l|}{ Faktor Predisposisi } \\
\hline Pendidikan ibu & 4,81 & $1,4-15,6$ & 0,009 & 5,25 & $1,4-19,1$ & 0,012 & 5,40 & $1,3-21,1$ & 0,015 \\
\hline Pendapatan per kapita & 4,88 & $1,3-17,2$ & 0,014 & 4,66 & $1,2-17,3$ & 0,021 & 3,84 & $1,0-14,8$ & 0,050 \\
\hline Ukuran keluarga & 4,77 & $1,2-18,2$ & 0,022 & 4,05 & $1,0-16,4$ & 0,050 & 3,25 & $0,7-14,4$ & 0,121 \\
\hline Pengetahuan & 3,54 & $1,1-11,0$ & 0,029 & 4,58 & $1,3-15,5$ & 0,014 & 4,72 & $1,3-16,6$ & 0,016 \\
\hline Sikap & 3,21 & $1,1-9,2$ & 0,030 & 4,06 & $1,4-15,4$ & 0,012 & 3,77 & $1,1-12,9$ & 0,035 \\
\hline \multicolumn{10}{|l|}{ Faktor pendukung } \\
\hline Partisipasi ibu & & & & 4,34 & $1,7-18,7$ & 0,004 & 4,45 & $1,5-18,7$ & 0,016 \\
\hline \multicolumn{10}{|l|}{ Faktor Pendorong } \\
\hline Dukungan tenaga kesehatan & & & & & & & 4,99 & $1,3-17,4$ & 0,013 \\
\hline Dukungan keluarga & & & & & & & 4,81 & $1,3-17,0$ & 0,014 \\
\hline-2 log likelihood & & 93,148 & & & 83,668 & & & 78,00 & \\
\hline $\mathrm{R}^{2}(\%)$ & & 0,275 & & & 0,343 & & & 0,380 & \\
\hline $\mathrm{n}$ & & 97 & & & 97 & & & 97 & \\
\hline
\end{tabular}

* Bermakna $(p<0,05)$ 
adanya peran dari petugas kesehatan yang dapat dilakukan melalui penyuluhan, konseling gizi, atau program-program yang lain. Peran aktif petugas kesehatan berdampak pada perubahan perilaku dalam masyarakat.

\section{KESIMPULAN DAN SARAN}

Berdasarkan uraian di atas, dapat disimpulkan bahwa faktor predisposisi yang berhubungan dengan perilaku ibu dalam pemberian MPASI adalah variabel pendidikan ibu, pendapatan per kapita, ukuran keluarga, pengetahuan, dan sikap. Faktor predisposisi yang tidak berhubungan bermakna secara statistik adalah variabel pekerjaan ibu, umur ibu, dan jumlah balita, Terdapat hubungan yang signifikan antara partisipasi ibu ke posyandu dengan perilaku pemberian MPASI. Faktor pendorong yang berhubungan dengan perilaku ibu dalam pemberian MPASI adalah dukungan petugas kesehatan dan dukungan keluarga sedangkan faktor yang tidak berhubungan dengan perilaku pemberian MPASI adalah variabel dukungan kader posyandu. Variabel yang dominan berdampak pada perilaku pemberian MPASI adalah variabel pendidikan ibu. Faktor predisposisi mempunyai kontribusi sebesar $27,5 \%$, faktor pendukung sebesar $6,8 \%$, dan faktor pendorong 3,7\% untuk terjadinya perilaku tidak baik dalam pemberian MPASI.

Saran yang dapat diberikan kepadadinas kesehatan agar dalam membuat program pencegahan maupun penanggulangan masalah gizi dapatdibuat menurut segmen sasaran berdasarkan tingkat pendidikan. Hal ini bertujuan untuk meningkatkan pengetahuan, sikap, dan perilaku ibu khususnya dalam pemberian MPASI pada baduta untuk mendorong terwujudnya perilaku kadarzi.

Perlu dilakukan upaya dan dukungan dari berbagai pihak (multisektor) untuk meningkatkan status ekonomi masyarakat (pendapatan) agar dapat memenuhi kebutuhan pokok untuk kehidupan sehari-hari.

Pelatihan pada petugas tenaga gizi puskesmas dan kader posyandu agar mempunyai pengetahuan, sikap, dan keterampilan yang memadai untuk melaksanakan program gizi khususnya program kadarzi. Khusus pada kader posyandu perlu diberi pelatihan penyuluhan atau konseling gizi dan kesehatan.

Bagi petugas puskesmas dan kader posyandu memberikan KIE (komunikasi informasi edukasi) melalui penyuluhan kepada ibu baduta secara teratur dan berkesinambungan, dengan menyesuaikan tingkat pendidikan ibu baduta. Materi KIE tentang pentingnya pemberian ASI ekslusif pada bayi, pemberian MPASI yang sesuai umur, porsi, jenis dan frekuensi serta bahaya pemberian MPASI sebelum bayi berusia 6 bulan. Bagi ibu baduta dan keluarga, sebaiknya dapat berpartisipasi aktif dalam kegiatan-kegiatan pelayanan kesehatan masyarakat, seperti ke posyandu dan puskesmas untuk meningkatkan pengetahuan dan sikap dalam pemberian MPASI pada baduta agar perilaku kadarzi dapat terwujud dalam keluarga ibu baduta dan masyarakat. Bagi peneliti selanjutnya, sebaiknya dapat melakukan penelitian dengan observasi perilaku pada responden dan jumlah sampel yang lebih besar sehingga hasil penelitian menjadi lebih akurat.

\section{RUJUKAN}

1. Soenaryo ES. Pengembangan Produk Pangan untuk Optimalisasi Tumbuh Kembang Anak: Persfektif Indofood. Makalah pada Prosiding Inovasi Pangan dan Gizi untuk Optimalisasi Tumbuh Kembang Anak. Jakarta; 2004.

2. Krisnatuti D, Yenrina R. Menyiapkan Makanan Pendamping Air Susu Ibu (PASI). Jakarta: Puspa Swara; 2000.

3. Dinas Kesehatan Kota Kendari. Profil Kesehatan Kota Kendari.Kendari: Dinas Kesehatan Kota Kendari; 2007.

4. Depkes RI. Pedoman Pendampingan Keluarga Menuju Kadarzi. Jakarta: Direktorat Bina Gizi Masyarakat; 2007.

5. Nurrohmah S, Gunanti IR. Tingkat Pengetahuan, Sikap dan Tindakan Ibu Rumah Tangga dalam Memilih Pangan Kemasan Berlabel.Makalah pada Prosiding Kongres Nasional Persagi dan Temu IImiah XIII, PERSAGI. Jakarta; 2005.

6. Khumaidi.Gizi Masyarakat.Institut Pertanian Bogor: Pusat Antar Universitas Pangan dan Gizi; 1994.

7. Lemeshow S., Hosmer, DW, Klar, J, Lwanga, SK. 1990. Adequacy of Sample Size in Health Studies. (Terjemahan) Pramono D, Kusnanto H. Yogyakart: Gadjah Mada University Press; 1997.

8. Soetjiningsih. Tumbuh Kembang Anak. Jakarta: Penerbit Buku Kedokteran EGC; 1995.

9. Notoatmodjo S. Promosi Kesehatan dan Ilmu Perilaku. Jakarta: Rineka Cipta; 2007.

10. Green LW, Kreuter MW, Deed SG, Patridge KB. Health Education Planning a Diagnostic Approach. (Terjemahan) Mamdy, Z., Tafal, Z., Kresno, S. Jakarta: Depdikbud RI; 1980.

11. Soetjiningsih. ASI Petunjuk Untuk Tenaga Kesehatan Seri Gizi Klinik. Jakarta: Penerbit Buku Kedokteran EGC; 1997.

12. Gunanti IR, Devi SR, Adriani M. Pemberdayaan Kader Posyandu Melalui Penerapan Metode Konseling Gizi dalam Upaya Meningkatkan Kualitas Pembinaan Program Keluarga Sadar Gizi (Kadarzi). Buletin Penelitian Sistem Kesehatan FKM Unair 2005; 8(1): 47-58.

13. Suhardjo. Sosio Budaya Gizi. Institut Pertanian Bogor: Departemen Pendidikan dan Kebudayaan DIKTI-PAU Pangan dan Gizi; 1989. 